\title{
ARTICLE
}

\section{THE GROWTH TREND OF PLANTED TREES (PINUS SYLVESTRIS L.) IN THE EARLY STAGE OF PLANTATION ESTABLISHMENT}

\author{
Batsaikhan G. ${ }^{1}$, Tsogtbaatar J. ${ }^{1}$ and Gerelbaatar S. ${ }^{2 *}$ \\ ${ }^{1}$ Division of Forest Resources and Forest Protection, Institute of Geography and Geoecology, \\ Mongolian Academy of Sciences, Ulaanbaatar, Mongolia \\ ${ }^{2}$ School of Engineering and Applied Sciences, National University of Mongolia, \\ Ulaanbaatar, Mongolia
}

ARTICLE INFO: Received: 18 Oct, 2018; Accepted: 13 Dec, 2018

\begin{abstract}
This study examined the growth of planted Scots Pine trees of different ages growing in the Tujyin Nars National park, located in Selenge aimag in the north of Mongolia. A total of seven, $50 \times 20 \mathrm{~m}(0.1$ ha) sized sample plots were established using a completely randomized sampling design. The tree growth monitoring was carried out between 2003 and 2017, by an annual repeated measurement at the end of each growing season. The total height, annual height increment and diameter at breast height were measured at sample plots and tree samples were taken for laboratory analysis. For statistical analysis, a One-way analysis of variance (One-way ANOVA) and F-test were applied. Our findings showed that the annual height $(F=15.21, P<0.0001)$ and radial increments $(F=15.76, P<0.0001)$ varied among plantations commensurate to their age. In our study, the highest height $(46.5 \pm 6.1 \mathrm{~cm})$ and radial $(4.1 \pm 0.8 \mathrm{~mm})$ increment were occurred in 12 and 10 years old plantations. Therefore, a strong positive correlation $(r=0.99)$ between tree increment and plantation age was observed in plantations below 12 years of age. After this age, increment values were relatively stable, which tended to gradually decrease with plantation age. Our findings confirm that initial planting design leads to overcrowding with plantation age; therefore, implementation of a thinning practice is necessary after a plantation reaches 12 years of age. The ever-decreasing trend of both radial and height increments in plantations beyond 12-years of age supports the importance of thinning as a practice to reduce competition and to support the growth of remaining trees in older plantations.
\end{abstract}

Keywords: plantation; Scots pine; increment; growth; trend;

\section{INTRODUCTION}

Forest plantations play an important role in carbon sequestration [12], storage [1], biodiversity conservation [2], soil erosion control [14] and forest ecosystem services
[9]. Survival and growth performance of planted trees in the early stage of plantation establishment are considered to be crucial indicators of further forest formation. The 
growth of planted trees is dependent on a number of factors, such as sufficiency of light [7], soil nutrient [15], competition [17], and initial planting design [8]. Ford et al. (1992) reported that the ever-increasing competition for light and spacing between individuals with increasing plantation age often leads to growth differentiation among planted trees.

Dominant trees show negative effect on suppressed trees via their shading [11]. Scientists have reported that thinning in the forest plantations is the most important silvicultural tools to improve their productivity [19]. In addition Scots pine is the most

\section{MATERIALS AND METHODS}

The study was carried out at the Scots pine plantations of Tujyin Nars National Park located in Selenge aimag. A total of seven $50 \times 20 \mathrm{~m}(0.1 \mathrm{ha})$ sized sample plots were established (in spring 2008) in Scots pine plantations, which were planted in 2003 (SP-1), 2004 (SP-2), 2005 (SP-3), 2006 (SP-4), 2007 (SP-5), and 1987 (SP-6), respectively. The climate in the study area is harsh, continental and with a precipitation peak between June important tree species in domestic timber production and forest ecosystem sustainability in the country. Tree planting activities in Mongolia began in 1971, however, the effectivness of reforestation and afforestation efforts is varied across forest regions. Several studies associated with seedling growth [23, $13,10,5]$ and biomass accumulation [6] have been done in plantations of northern Mongolian boreal forests. In this study, we aimed at 1) assessing the growth trend for planted trees, and 2) developing a scientific basis for further silvicultural management in planted forests.

and August. For the period of 2003-2014, the nearest meteorological station in Sükhbaatar, located 15 to $20 \mathrm{~km}$ north-west at an altitude of $660 \mathrm{~m}$ (N50¹4'22.30" and E106 $\left.{ }^{\circ} 11^{\prime} 33.54^{\prime \prime}\right)$, reported an average temperature of $0.31{ }^{\circ} \mathrm{C}$ and an average total annual precipitation of 249.8 $\mathrm{mm}$. The dry season extends from March to June in spring and from August to October in autumn [20].

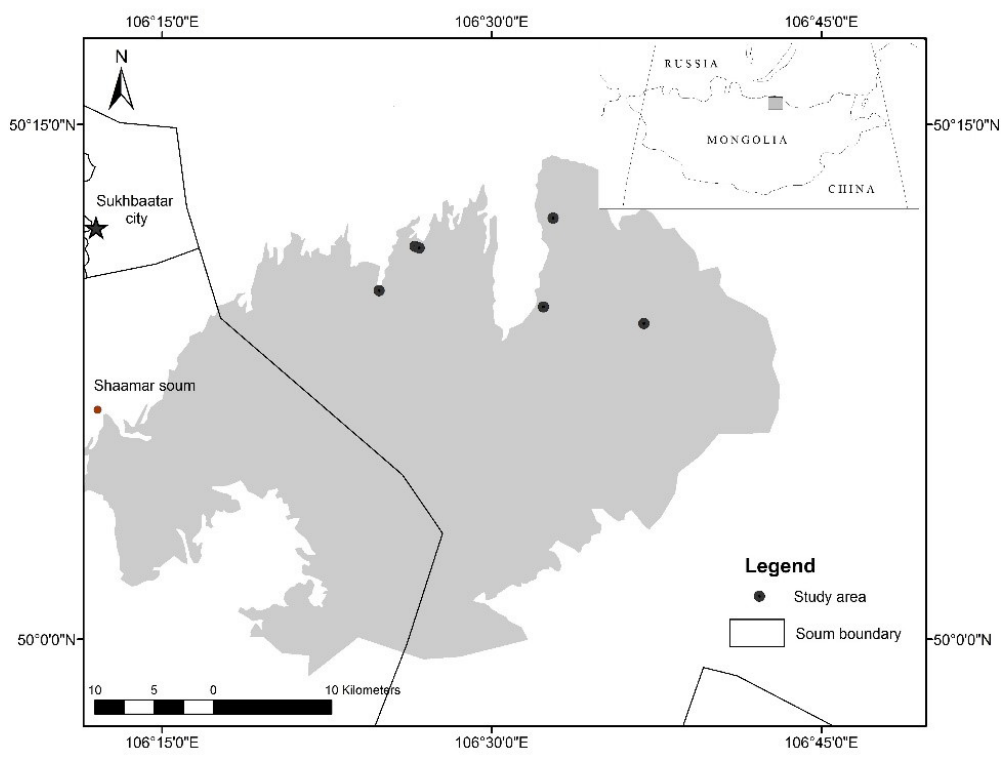

Figure 1. Location of the sample plots 
Two year-old bare-root seedlings of Scots pine were transplanted manually using the slit planting method. We used a planting bar to create a V-shaped slit in the ground, inserted the seedling into the slit and pushed the soil back firmly around the roots. The initial planting density of each plantation was 2500 seedlings per hechare $(4.0 \times 1.0 \mathrm{~m}$ spacing $)$. All field measurements and data collection were carried out annually in August and October between 2008 and 2017. Annual field measurements of seedlings included: diameter at stem base, total height and annual height increments. We assessed the survival status on each plot by counting the number of live and dead individuals. Based on the measurements in the sample plots, the survival rate of each plantation was estimated annually (2008-

\section{RESULTS AND DISCUSSION}

\section{Height and radial increment with plantation age}

The height and radial growth are the main indicators of the forest growth and productivity, and they become a scientific basis for decision makers. The annual height $(\mathrm{F}=15.21, \mathrm{P}<0.0001)$ and radial increments $(\mathrm{F}=15.76, \mathrm{P}<0.0001)$ varied among plantations with plantation age (Fig. 3, 6). According to our study, the highest height $(46.5 \pm 6.1 \mathrm{~cm})$ and radial increment $(4.1 \pm 0.8 \mathrm{~mm})$ were recorded in plantations of 12 and 10 years of age.

Therefore, a strong positive correlation $(r=0.99)$ between tree increment and plantation age was observed in plantations below 12 years
2017). Tree height was measured to the nearest $0.01 \mathrm{~m}$ with a measuring tape and diameter at stem basis was measured to the nearest $0.1 \mathrm{~cm}$ with calipers.

We measured the annual tree-ring width of medium-sized samples ( 5 cores from each plot) at the Laboratory of Dendrochronology at the Mongolian Academy of Sciences (MAS). For the analysis of the seedling growth, we used the One-way analysis of variance (One-way ANOVA) method to determine statistically significant differences in means among variables and sites. There fore, we used a F-test to determine equality of group means $[3,16]$. We also used AutoCAD and "Forest window" software to draw the spatial distribution and crown dimension of each tree at the sample plot.

of age (Fig. 2). After this age, increment values relatively stabilized and tended to gradually decrease with plantation age. This may be a consequence of enhanced crown closure between individuals along the planting row. Higher variation was found in radial increment than in height increment. Our findings indicated that planting by this initial planting design used for plantation establishment requires the implementation of a thinning operations after a plantation reaches since 12 years of age to reduce competition and promote the growth of remaining trees. However, we found a stronger influence of overcrowding on radial increment in plantations. 

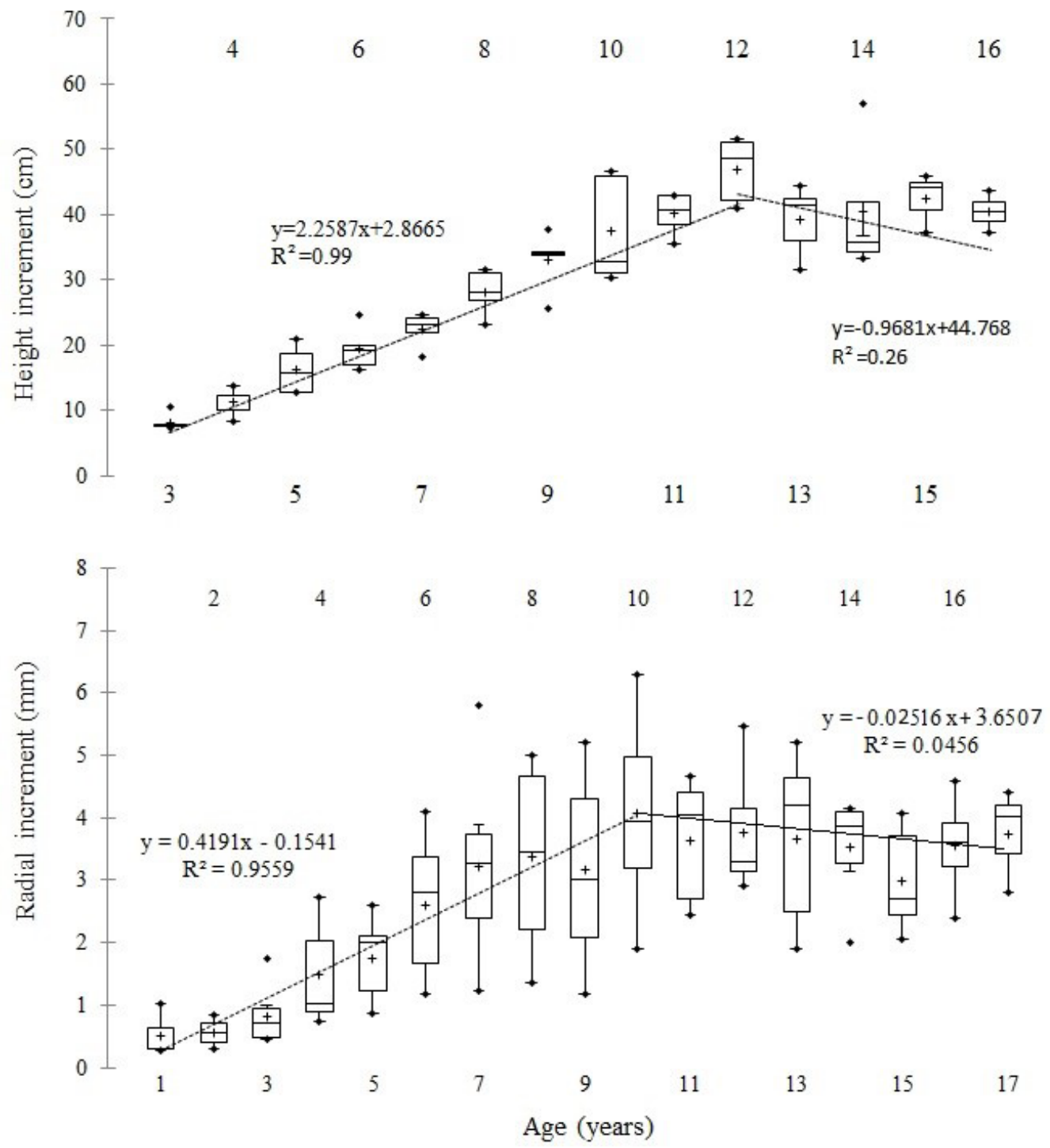

Figure 2. Height and radial increment of planted trees 


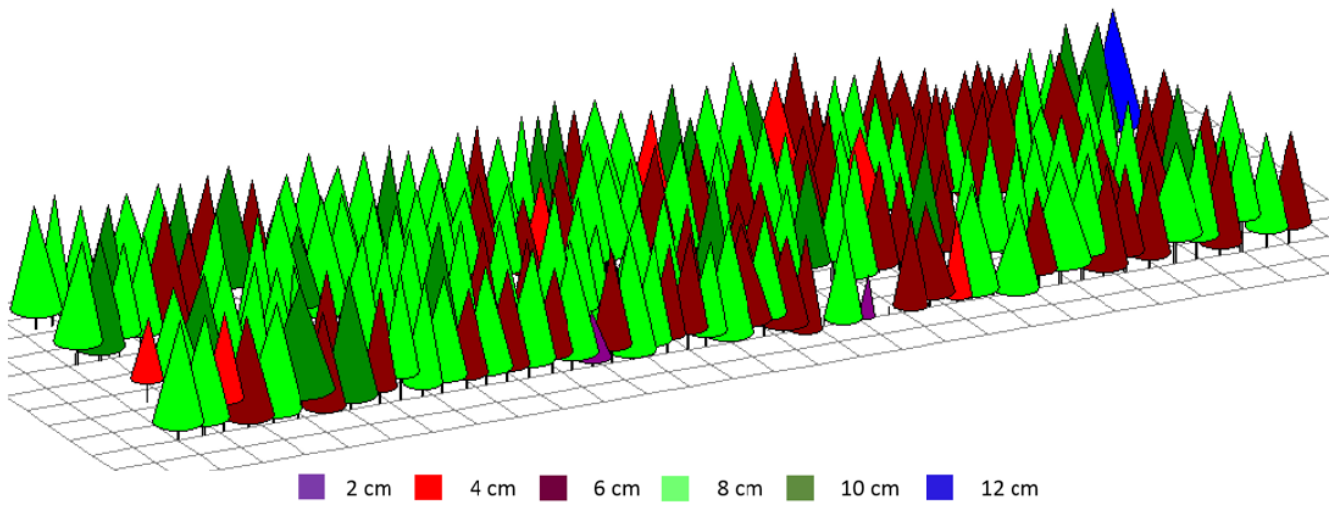

Figure 3. Distribution of planted trees by diameter classes

\section{Growth variation and distribution of planted trees by diameter classes}

The spatial distribution and crown dimensions of planted trees classified into diameter classes $(2 \mathrm{~cm}$ class) are shown in the example SP-1 (Fig. 3). The results of the study showed that the majority of planted trees was attributed to the average growth (83.1\%) (in this case 6 and $8 \mathrm{~cm}$ ), and the remaining part belonged to the accelerated $(10.3 \%)$ and retarded growth $(6.6 \%)$.

The tree distribution map drawn with

\section{Effect of planting design on crown development}

The initial planting design plays an important role for the future stand formation by considering the regulation of competition and tree growth. Salminen and Varmola (1993) emphasized that artificial regeneration makes it possible to regulate the growth space of forest trees. In Mongolia, there is a common practice of a distance of 4 meters between adjacent furrows and a distance of 0.7 to $1.0 \mathrm{~m}$ between seedlings.

According to common practice in Mongolia, the furrows were dug in the transverse direction of solar radiation. A rectangular planting design results in lower total production due to the early start of competition between the trees in a row and because the entire growth space in
AutoCAD demonstrated that such small distance between planted trees, which ranged from $0.7 \mathrm{~m}$ to $1 \mathrm{~m}$, created the prerequisites for a relatively early start of crown closure and competition between individuals (Fig. $3)$. The increased competition rate between planted trees showed a limiting effect on stand productivity. The ever-decreasing trend of both radial and height increments after 12-years of plantation age suggested an importance of thinning as a tool to reduce competition and support the growth of remaining trees.

this design is not used efficiently. A relatively symmetric crown development was observed until 10 years of plantation age, and then the crowns tended to become more asymmetric and the branches thicken in the direction of the free space (Fig. 4). After this period, the differentiation in the crown diameter parameters and their standard deviations to the north and south directions tended to grow gradually with plantation age.

Scots pine is a light-demanding tree species and has the ability to grow in nutrient-poor soils $[18,22]$. Especially, the relatively faster growth and symmetrical crown development, observed during the first decade, are related to the absence of competition between individuals and the existence of light sufficiency in planted forests. 


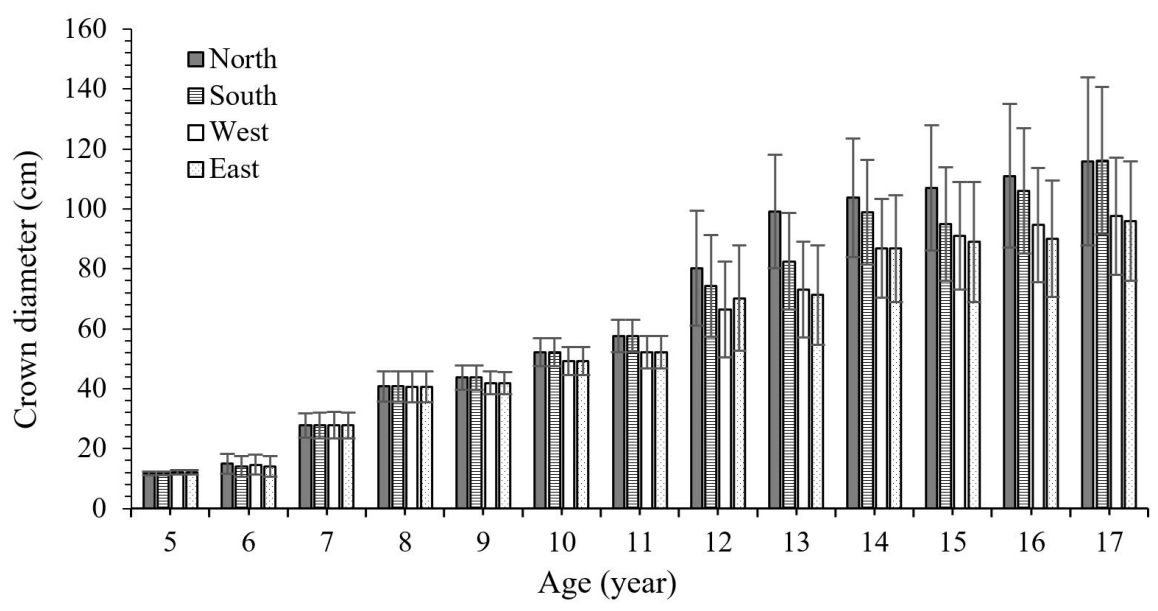

Figure 4. Crown size to the directions

a

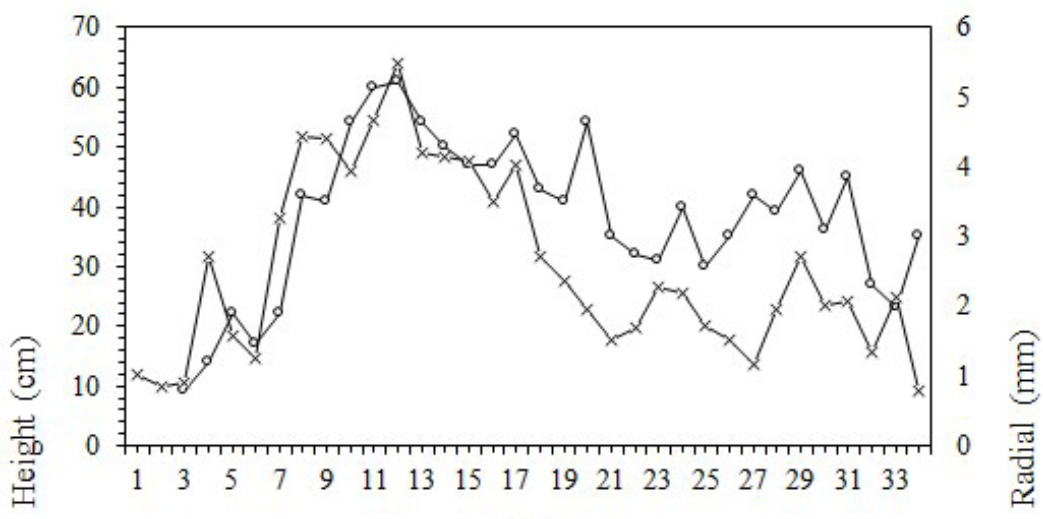

$\mathrm{b}$

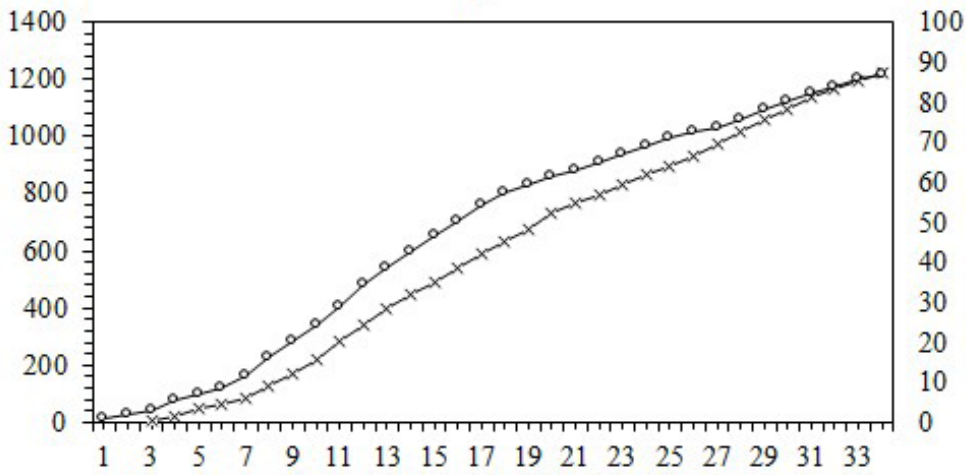

Age (year)

$$
-x-\text { Height } \rightarrow-\text { Radial }
$$

Figure 5. Increment and cumulative growth trend of planted trees (SP-6),

a) height and radial increment, b) cumulative growth 
To provide intensive growth with symmetrical crown development, our findings confirm this idea to implement thining operations in appropriate time in artificial forest plantations in Mongolia.

Zutter and Miller (1998) emphasized that canopy closure may have a long-term influence on woody and understory plant associates. In order to involve more extended period of tree growth, we measured height and radial increments on the samples taken from 34-yearold plantation (Fig. 5). Additionally, intensified overcrowding and limitation of growing space in the stand showed obvious negative impacts on both height and diameter increment. Overall, looking at cumulative growth trend, we may distinguish two phases of tree growth: firstly, the ever-increasing exponential growth before the crown closure; and secondly, reduced growth with the intensification of the crown closure due to limitation of growing space in the stands. Abandoned silvicultural treatments, including thinning and protective measures on forest plantations, can cause self-thinning and the formation of trees less resistant to disturbances. Growth will be increased with forest management intensity, bearing in mind that even intensive management requires certain investment in forest plantations in the study region.

Acknowledgements: The study was supported by the Mongolian Forest Forum. The authors would like to acknowledge colleagues at the "Tujyin Nars" National Park Administration for providing human resources necessary for the field data collection. We also thank to Dr. P. Battulga and Ch. Chinzorig for the valuable advice, and to Misha Goforth for the English improvement during the article writing.

\section{REFERENCES}

[1] Chen Y, Liu Z, Rao X, et al. 2015. Carbon storage and allocation pattern in plant biomass among different forest plantation stands in Guangdong, China. Forests, 6: pp. 794-808.

[2] Eycott, A. E., Watkinson, A. R., Dolman, P. M., 2006. Ecological patterns of plant diversity in a plantation forest managed by clearfelling. Journal of Applied Ecology. 43(6): pp. 1160-1171.

[3] Fisher. R. A. (1925). Statistical Methods for research Workers. Oliver and Boyd (Edinburgh). p. 336. Available online: http://www.haghish.com/resources/materials/ Statistical_Methods_for_Research_Workers.pdf.

[4] Ford, E. D., Sorrnsen, K. A. (1992). Theory and models for inter-plant competition as a spatial process. Eds. D. L. Deangelo's and L. J. Gross, Routledge, Chapman and Hall, London. pp. 363-407.

[5] Gerelbaatar, S. (2011). Specifics of the formation of Scots pine (Pinus sylvestris L.) plantation. Ph.D thesis, Ulaanbaatar, Mongolia. p. 123 (In Mongolian).

[6] Gerelbaatar, S., Baatarbileg, N. (2013).Above-ground Biomass Allocation in a Planted Forest in a Semi-arid Region of Northern Mongolia, Journal of Agricultural Science and Technology, 3: pp. 216-220.

[7] Hattori, D, Kenzo T., Kendawang, J. J., et al. (2009). Effect of light intensity and soil physico-chemical properties on seedling mortality and growth of six dipterocarp species planted for rehabilitation of degraded grassland, secondary forest and logged forests in Sarawak, Malaysia. Japanese Journal of Forest Environment, 51(2): pp. 105115.

[8] Hattori. D., Kenzo, T., Yamauchi, N., et al. (2013). Effect of environmental factors on growth and mortality of Parashoreea macrophylla (Dipterocarpaceae) planted on 
slopes and valleys in a degraded tropical secondary forest in Sarawak, Malaysia. Soil Science and Plant Nutrition, 59: pp. 218-228.

[9] Hector, A., Bagchi, R. (2007). Biodiversity and ecosystem multifunctionality. Nature, 448: pp. 188-190.

[10] Iderchuluun, J., Tsog.t, Z. (2009). Survival and growth of the transplanted planted seedlings. Journal of Scientific Research, Mongolian University of Science and Technology, Special issue dedicated to 85th Anniversary of Forestry Development in Mongolia. pp. 124-129. (In Mongolian).

[11] Kikuzawa, K., Umeki, K. (1996). Effect of canopy structure on degree of asymmetry of competition in two forest stands in northern Japan. Ann Bot 77: pp. 565-571.

[12] Kongsager, R., Napier, J., Mertz, O. 2013. The carbon sequestration potential of tree crop plantations. Mitigation and Adaptation Strategies for Global Change, 18: pp. 1197-1213.

[13] Khishigjargal, M. (2002). Growth specifics of young planted trees in western Khentii mountains. MSc thesis. Ulaanbaatar, Mongolia. (In Mongolian).

[14] Lawson, S. S., Michler, C. H. (2014). Afforestation and regeneration - Not all trees are created equal. Journal of Forestry Research, 25(1): pp. 3-20.

[15] Löf, M, Karlsson, M., Sonesson, K., Welander, TN. (2007). Growth and mortality in underplanted tree seedlings in response to variations in canopy closure of Norway spruce stands, Forestry, 80(4): pp. 371-383.

[16] O'Brien, R. G. (1979). A General ANOVA Method for Robust Tests of Additive Models for Variances, Journal of the American Statistical Association, 74(368): pp. 877-880.

[17] Osunkoya, O. O., Othman, F. E., Kahar, R. S. (2005). Growth and competition between seedlings of an invasive plantation tree, Acacia mangium, and those of a native Borneo heath-forest species, Melastoma beccarianum. Ecological Research, 20(2): pp. 205214.

[18] Picon-Cochard, C., Coll, L., Balandier, P.(2006). The role of below-ground competition during early stages of secondary succession: the case of 3- year-old Scotspine (Pinussylvestris L.) seedlings in an abandoned grassland. Oecologia148: pp. 373-383.

[19] Pothier, D. (2002). Twenty-year results of pre-commercial thinning in a pine stand. Forest Ecology and Management, 168: pp. 177-186.

[20] Regzedmaa, M. (2008) Climate Resources and Changes of Meteorological Data of Selenge Province. Sükhbaatar, pp. 11-25. (In Mongolian), Foundation for Statistical Computing: Vienna, Austria (2013) Available online: http://www.R-project.org/ (accessed on 24 September 2017).

[21] Salminen, H., Varmola, M. (1993). Influence of initial spacing and planting design on the development of young Scots pine (Pinus sylvestris L.) stands. Silva Fennica 27(1): pp. 21-28.

[22] Sanchez-Gomez. D., Zavala, M. A., Valladares, F. (2006). Seedling survival responses to irradiance are differentially influenced by low-water availability in four tree species of the Iberian cool temperate Mediterranean ecotone. Acta Oecologia 30: pp.322-332.

[23] Tsogt, Z., Enkhjargal, J. (2000). Effect of some climate factors on planted tree growth. Scientific Journal of National University of Mongolia, Special Issue, 148(1): pp. 8593.

[24] Zutter, B., Miller, J. H. (1998). Eleventh-year response of loblolly pine and competing vegetation to woody and herbaceous plant control on a Georgia flatwood site. Southern Journal of Applied Forestry. 22(2): pp. 88-95 
Vol. 58 No 04 (228) 2018 